\title{
Perception of the Benefits and Features of Health Insurance Policies Offered by the Employers: Empirical Findings from Saudi Arabia
}

\author{
Hashem Abdullah AlNemer ${ }^{1}$ \\ ${ }^{1}$ Department of Finance and Insurance, College of Business, University of Jeddah, Saudi Arabia \\ Correspondence: Hashem Abdullah AlNemer, Department of Finance and Insurance, College of Business, \\ University of Jeddah, Saudi Arabia. E-mail: halnemer@uj.edu.sa, dr.hashem.alnemer@gmail.com
}

Received: March 15, 2018

doi:10.5539/ijbm.v13n6p214
Accepted: May 2, 2018

Online Published: May 15, 2018

\begin{abstract}
Government of Saudi Arabia is concerned and committed to improve the living standards of its people by enhancing, and standardizing healthcare service and education industry of the country which accounted for 36 percent of the budget in 2017, however, the spending was influenced by drop in oil revenues. The spending on healthcare services was reduced by $34 \%$ in 2016, from $\$ 42.67$ billion in 2015 to $\$ 27.97$ billion in 2016 (MOH, 2016). The decrease in government spending came as a strategy to increase the participation of private healthcare sector expenditure. Consequently, Ministry of Health $(\mathrm{MOH})$ and Council of Cooperative Health Insurance (CCHI) have made medical insurance a must for non-Saudi residents (Expatriates) and their families. It's the responsibility of Sponsor (Employer) to provide medical insurance to the expatriate and his/her family in Saudi Arabia. Accordingly, Health insurance in the form of Compulsory Employment-Based Health Insurance (CEBHI) was introduced in Saudi Arabia to regulate and ensure the provision of healthcare for expatriates working in the private sector, whilst providing financial protection against their healthcare expenses. It is prohibited for any employer not to participate in CEBHI, non-compliance to this law is punishable offence. However, despite these strong regulation, which comes in favor of expatriates, a number of complains been raised by expatriates of poor health care services due to employer unwillingness to provide proper health insurance policy, as a result of expensive premium. No studies have been conducted to systematically document expatriates' perceptions in the health insurance industry. This paper attempts to fill the gap. The paper reports results about the perceptions of 324 expatriates at private sector in Saudi Arabia. The research found that most expatriates' bout their policy from an intermediary with a weak knowledge about the insurance business, they also indicate their willingness to attend awareness lessons to educate themselves about the features of their health insurance policy. Expatriates also clarified that the policy they possess have a weak quality with limited benefits. The results indicated that there is a need to launch a measuring and controlling mechanisms, to control employer compliance with CEBHI regulations, to protect expatriates' rights in getting proper health care service by having the right health insurance policy.
\end{abstract}

Keywords: Saudi Arabia, expatriates, health insurance, insurance regulations

\section{Introduction}

Health Insurance is a generic term, encompassing several types of insurance contracts, which, though related, are intended to protect against different risks. Until recently, there was little consistency in the terminology used in referring to health insurance. It was called "accident and health", "accident and sickness", "disability" and a number of other terms all of which are gradually giving way in favor of the general term "Health Insurance"(Elliot \& Vaugham, 1972, p. 262). Health Insurance deals with two principal types of losses. The first is the expense of medical treatment and the second is the income that an insured person would have earned but is unable to earn during a period of disability (Crane F, 1980, p. 23).

During the past few decades, health and health services have improved greatly in terms of quantity and quality. Gallagher has stated that: "Although many nations have seen sizable growth in their health care systems, probably no other nation (other than Saudi Arabia) of large geographic expanse and population has, in comparable time, achieved so much on a broad national scale, with a relatively high level of care made available to virtually all segments of the population" (Gallagher, 2002). According to Ansari (2011), since reforms initiated in Saudi insurance industry in 2004, insurance industry registered remarkably high growth rate in 
premium, large participation by local companies entering the insurance market, and also government established sound regulatory system to develop the insurance industry of Saudi Arabia to international standards. According to the World Health Organization (WHO, 2000), the Saudi health care system is ranked $26^{\text {th }}$ among 190 of the world's health systems. It comes before many other international health care systems such as Canada, Australia, New Zealand, and other systems in the region such as the United Arab Emirates, Qatar, and Kuwait. Such improvements were due to the government of Saudi Arabia, which has given high priority to the development of health care services. The Saudi government's expenditure on health not only still provides the majority of the healthcare budget like other GCC countries, but also provides the highest percentage amongst GCC countries. (WHO, 2000), the labour law published in 1969, stated that employers were required to provide medical treatment for employees. However, the law was not enforced for a variety of reasons. First of all, the law did not address the nationality of the workers that would be affected (Saudi or non-Saudi). Because there was no mechanism or clear method as to how the law should be implemented. Secondly, the number of all workers was less than 1,200,000 and therefore the load on medical services was insignificant, which shows no impact on the operation of existing health services (Al-Rabeeah, 2000).

By 1999, Health insurance in the form of Compulsory Employment-Based Health Insurance (CEBHI) was introduced in Saudi Arabia but the actual implementation began in 2006.The CEBHI's full implementation finished by November 2008. CEBHI was implemented to all companies regardless of the number of employees. CEBHI is applicable primarily to expatriate working in Saudi Arabia. The CEBHI scheme was implemented to regulate and guarantee the provision of healthcare for expatriates working in the private sector, whilst providing financial protection against their healthcare expenses. CEBHI has another benefits of improving utilization of the government healthcare budget, reducing the load on the government's healthcare providers, and increasing the participation of private healthcare sector expenditure. Another aim of CEBHI is to increase expatriate access to private healthcare, allowing better government spending on healthcare services by reducing expatriate access to government resources (CCHI, 2009). Thus, the CEBHI scheme is not only compulsory, but a financial fine must be paid by employers who fail to follow the policy. Employers could also lose their right to hire expatriate workers if they failed to pay premiums for their worker (Cabinet of Ministers, 1999). This approach is vital for achieving a health system's basic goal of improving health status, providing financial protection against the cost of catastrophic illness, and assuring customer satisfaction (Schieber, 2005). Such a system will allow CEBHI to protects the workers from the increasing cost of premiums over time. Subsequently, no expatriate can obtain or renew the residency card without an official document confirming that he/she has a health insurance policy that is equivalent to the residence permit period.

\section{Literature Review and Hypotheses Development}

The concept of quality is more important today than ever before to survive and remain competitive. Because the requirements and expectations of all interested parties must be identified and met. Oakland, clarified that Quality is often used to signify 'excellence' of a product or service (Oakland, 1995). He also defines quality as 'meeting the customer requirements' (Oakland, 1995). The insurance industry worldwide is being penalized for the heavy legacy of poor standards, i.e. poor standards of selling especially selling through agencies, poor standards of product design, small print syndrome and excessive product complexity and equivalent offering with rare service quality measurement especially in the life insurance field (Francis, 2002). Therefore, a better service quality may be the only way to differentiate the insurance industry from other service sectors (Sherden, 1987; Siddiqui et al, 2010). Meltzer (1997) also asserts that quality in insurance means providing customers insurance products/service that they want, when they want them, a requirement that demands insurers' understanding of their business, and being attentive to their customers' needs by providing products and services that meet their needs. A number of authors clarified that the poor service quality in the insurance industry existed as a result of a number of factors. Of which, under-investment in it (Gow, 2000; Marwa, 2005), poor distribution channels (Diacon, 1995; Mccabe et al.,1997), poor staff training (Friedman, 2002; Pratt, 2002; Voelker, 2000; Marwa, 2005), failure to focus services to meet customer needs (Wells et al., 1998; Friedman, 2001a, 2001b; Cooper et al., 2001), lack of differentiation in the insurance industry (Goch, 1999; Drury, 2003; Bhatty, 2007), distrust of the industry (Darcy, 1996; Smith, 1996; Marwa, 2005). On the other hand, the practicing success of the service quality in 1990s, for the manufacturing, banking, hospitality and other service industries in the USA. Had led the adoption of theses quality practices by the insurance industry and to adopt its own quality standards and sensitization guided by the Quality Insurance Congress (QIC). QIC found to create an insurance system that enhances customer satisfaction in the insurance industry. Accordingly, a number of improvements had been witnessed in the service quality of insurance industry. It's important for insurance operators to find ways to determine customer satisfaction. Policyholders perceptions of insurers' service quality can be a good indication 
for that. Accordingly, Wells et al. (1995) has identified three main findings for this assumptions. Higher levels of perceived service quality lead to lower complaints ratios, customer awareness of their rights leads to a reduction in dissatisfaction, policyholders' actual knowledge about the insurance product has a negative relation with service quality. However the findings of Saaty and Ansari (2011), show that the demand for insurance in Saudi Arabia was driven by law as most of the users were buying only compulsory insurance just to comply with the law as motor insurance was made compulsory.

One of the main market conduct problem faced by Insurance companies are the issue of intermediaries and regulations, which vary from one jurisdiction to another in regulating intermediaries (Alnemer, 2015a). Saudi Arabian Monetary Agency "SAMA" asserted that intermediaries should comply with the internationally accepted best practice, such as fulfilling their obligations towards policyholders and insurance company, acting in honest and manner way. They also have to acquire a good knowledge, enough experience and proper training about insurance products and service (SAMA, 2011).

Alnemer (2015b) asserted that, the majority of policyholders of are against the idea of selling insurance products via intermediaries. Policyholders believe that insurance products shall be sold by the insurance company itself. Policyholders also believe that intermediaries in Saudi Arabia have a weak knowledge about insurance business (Alnemer, 2015b). Such findings come in contrast with the regulations made by SAMA, as they have asserted that intermediaries shall communicate all related information to policyholders such as, details of coverage, timing to accept or reject insurance claims, etc. Furthermore, the International Association of Insurance Supervisors IAIS (2011) has identified the ICP 18 as one of the main principles to improve intermediaries' roles in the insurance industry. ICP 18, address the importance of proper commercial and insurance knowledge, license, good reputation, policyholders fund protection (IAIS, 2011).

Expatriates awareness and knowledge about their health insurance features and benefits are based on proper transformation. Hence, it's very important for the insurance company to convey the proper knowledge for their expatriates' clients. However, study conducted by Alnemer (2015b) indicated that policyholders have overall low perceived information from insurance company which leads to a very weak knowledge about the basic principles of their insurance policy. The results showed that although respondents demonstrated a high level of awareness of the existence of the insurance policy, the level of knowledge is deemed low. The results also indicate that there is a need for the insurance company to spend more efforts to educate their policyholders about their rights and obligations. The future of the insurance industry is dependent on proper understanding of the business and rights of policyholders by different industry stakeholders which includes the customers, insurance company and the regulators (Alnemer, 2015b). Ansari (2012) also found that the primary motivating factor for purchasing insurance in Saudi Arabia was the legal factor due to which the buyers purchase only the compulsory insurance namely motor insurance and health insurance.

Such findings come in contrast with SAMA's regulations. SAMA's have identifies a minimum requirements and educational levels of insurance company's employees, and an obligatory examination of a person providing insurance and reinsurance services (SAMA, 2008).

Disclosure is the way of providing information to the prospective policyholders. It will enable them to make proper and informed choices of the suitability and quality of insurance product, which can suit customers' needs, to prevent policyholders suffering when insolvency situations are encountered. Hence, disclosure considered an important aspect to reflect a good efficiency of the financial market (IAIS, 2002). Alnemer (2015c) indicated that despite the fact an updated and active disclosure mechanism leads to the success of any company, policyholders in Saudi Arabia have overall perceptions about insurance company's disclosure variables appears to be low (Alnemer, 2015c).

A study by Morrisey and others, concluded that the main reason employers did not offer health insurance to employees, was the high premium variability (Morrisey et al., 1994). Small firms may control the expensive premium variability by keeping workers who were expected to utilize less healthcare services. In other words, the enforced link between employment and health insurance may result in the prevention of individuals with expected high healthcare costs from being employed by small firms (Kapur, 2004, Kapur et al., 2008). Hence, people without health insurance or with disrupted coverage are less likely to have usual healthcare services such as primary healthcare, and more likely to have unmet healthcare needs (Carlson et al., 2006, Kasper et al., 2000, Newacheck et al., 1998, Callahan and Cooper, 2005, Lillie-Blanton and Hoffman, 2005, Waidmann and Rajan, 2000a; 2000b)

It has been reported that health insurance payments through OOP lead to inequity, increased poverty, and disastrous health expenditure (ILO, 2008). This method is not necessarily affordable for the poor, or people with 
low incomes, so it could be considered regressive (Mills, 2007). Reduction of direct payments is very important for increasing the equity of financing (Mills, 2007). The OOP payments were $38 \%$ of private health expenditure and $9.7 \%$ of the total health expenditure in Saudi Arabia (Sekhri \& Savedoff, 2005), compared to $49.3 \%$ of the average value of OOP expenditure in 45 low-income countries (ILO, 2008). Hence, the implementation of the CEBHI in Saudi Arabia has reduced OOP payments. Consequently, expatriate workers' co-payments towards the invoice have been determined by the new policy as not to exceed $20 \%$ of the invoice or SR100 (USD26.67) (CCHI, 2009a; 2009b). Workers pay a fixed amount of money to avoid any concern that the co-payment or co-insurance could increase over time.

Different studies argue that health insurance coverage alone may not be significant enough to increase access for minorities due to variations in the quality of healthcare providers, differences in culture, linguistic differences, discrimination, and attitudes about healthcare (Fiscella et al., 2002, Zuvekas \& Weinick, 1999). Other studies note that factors such as job characteristics and personal characteristics are equally important to health insurance (Zuvekas \& Tallaferro, 2003). David Cutler and Brigitte Madrian (1998) observed that health insurance influenced the labour market by lowering wages and changing the composition of employment (Cutler \& Madrian, 1998). In another study, Cutler demonstrated that workers, rather the employers, refused to take up health insurance because of the rising premiums (Cutler, 2003).

Although, CEBHI is mandatory and health insurance companies determine the premium based on risk pooling, not the need, or income (CCHI, 2009b). Health insurance coverage, benefits, premiums and co-payments are based on an agreement between the employer and the health insurance company (Fronstin, 2000). These factors could be used to increase the premium or the co-payment, or reduce the healthcare benefits in the policy for the workers. Bundorf (2000) studied the influence of employers on the health insurance that workers received by using employer economic incentives when choosing health benefits for employees with heterogeneous preference for coverage. He found that in general, employers respond to the choice of their employees, but some workers do not receive the desired health insurance due to both the level and variation of their characteristics (Bundorf, 2000). Hansen (2001) studied the factors that influenced the small business employers' decision to offer health insurance to their workers; employers use health insurance coverage to attract highly skilled employees but employers are less likely to provide health insurance coverage if the insurance coverage is very expensive.

\section{Statement of the Problem}

One of the main purpose of introducing CEBHI, is to regulate and guaranteed the provision of healthcare in the form of health insurance for expatriates working in Saudi Arabia at the private sector, whilst providing financial protection against their healthcare expenses. The regulation is there to guaranteed a good quality health insurance to expatriates, while protecting expatriates from the increasing cost of premiums over time. However, despite the fact that CEBHI made health insurance obligatory for the expatriates, many employers refuse to offer a health insurance policy to their expatriates' employees because of the higher premium price. Employers might also offer a health insurance policy based on income, not on the need or risk pooling. Low quality insurance will lead expatriates to pay out pocket, which causes financial hard ship for them. As the majority of expatriates in Saudi Arabia are working in jobs for which they are overqualified, most are not employed in a job that reflects their actual education, which might reduce their salary.

\section{Objectives of the Study}

The primary objective of this study is to find out the perception of expatriate towards health insurance policies which is mandatory in Saudi Arabia under CEBHI.

\section{Methodology}

The present study is quantitative and descriptive study based on primary data collected from respondents living in Saudi Arabia as an expatriate.

Research Instrument: Since the study was based on primary data a closed ended structured questionnaire was developed. The identified variables were selected carefully from existing literatures. The utility of the results depends on reliable data therefore the questionnaire which was originally developed in English language was also translated into Arabic language as it the spoken language in the country and a large number of expatriates are from gulf region such as Egypt, Jordan, Lebanon, Yemen and others. Based on the comfort of the respondent's language English and Arabic questionnaires were distributed.

With the help of the research assistants a total of 500 questionnaires were distributed in both languages from which 383 filled questionnaires were received where 324 were found useful, a response rate of $85 \%$. 
Descriptive analysis such as percentage, frequency was performed to achieve the proposed objectives in this study.

\section{Results}

This section presents the research results in relation with the objectives and aims of the proposed study earlier. Quality of the research findings depends mainly on the reliability of empirical data. Accordingly, reliability was evaluated by assessing the internal consistency of the items representing each factor using Cronbach's Alpha. An acceptable value of (0.867) was calculated as the reliability Cronbach alpha. Hence, the data on these variables are reliable and consistent with research standards.

Table 1. Purchased health insurance policy from insurance intermediaries

\begin{tabular}{llll}
\hline \multirow{4}{*}{ Valid } & Options & Frequency & Percent \\
\cline { 2 - 4 } & No & 153 & 47.2 \\
& Yes & 171 & 52.8 \\
& Total & 324 & 100.0 \\
\hline
\end{tabular}

Table 1, discuss the sensitivity of selling health insurance policy via the right and capable personnel. Hence, it's wise to figure out if expatriates bought their health insurance policy from the insurance company selling-personnel or foreman intermediary. As SAMA stresses that intermediaries shall act in an honest, transparent and fair manner to fulfill their obligations towards policyholders and the insurance company. Surprisingly, $171(52.8 \%)$ expatriates indicated that they have bought their health insurance policy from an intermediary. Their answers came in parallel with hypotheses 1 , which assumed that the majority of health insurance policy is sold via intermediaries. Such an answer should be reviewed carefully to find out if intermediacies are in adherent to the regulations and rules that been posted by SAMA in regards to the right acts of intermediaries toward policyholders.

Table 2. Preference to select health insurance source of selling

\begin{tabular}{llll}
\hline \multirow{4}{*}{ Valid } & Options & Frequency & Percent \\
\cline { 2 - 4 } & No & 102 & 31.4 \\
& Yes & 222 & 68.6 \\
& Total & 324 & 100.0 \\
\hline
\end{tabular}

Table 2, explore expatriates' preferences to select the right personnel to buy health insurance from. The question also asked if expatriates wants to listen to health insurance policy from the intermediaries or from the company employees directly. The results were astonishing that $222(68.6 \%)$ expatriates want to buy their health insurance policy from the insurance company itself. The results come in parallel with hypotheses 2 , also comes in parallel with the research that been made by Alnemer (2015) that intermediaries had a weak knowledge about insurance business, otherwise policyholders would have no problem to buy their insurance policy from them.

\subsection{Expatriates Awareness of Having a Qualified Health Insurance Policy}

Table 3. Do you prefer to attend an education sessions explaining the feature of your health insurance policy

\begin{tabular}{llll}
\hline \multirow{4}{*}{ Valid } & Options & Frequency & Percent \\
\cline { 2 - 4 } & No & 92 & 28.3 \\
& Yes & 232 & 71.7 \\
& Total & 324 & 100.0 \\
\hline
\end{tabular}

Table 3, explore the need of expatriates to learn and be aware of the feature of the health insurance policy they possess. As its been stressed by SAMA (2008) that insurance company should keep their employees' skills and knowledge of the insurance business up-to-date and be informed of the products and services offered by the company. Surprisingly, 232 (71.7 \%) expatriates indicated that they are in need of an education mechanisms. Expatriates replies comes in contrast with hypotheses 3, as they haven't exposed to a wide disclosure channel explaining the feature of the possess policy. 


\subsection{Information Availability of Health Insurance Policy}

Table 4. Sufficient Information is available about the health insurance policy you have as well as the company you bought the insurance policy from

\begin{tabular}{llll}
\hline & Options & Frequency & Percent \\
\cline { 2 - 4 } Valid & Strongly Agree & 13 & 4.3 \\
& Agree & 38 & 11.8 \\
& Natural & 80 & 24.8 \\
& Disagree & 132 & 40.4 \\
& Strongly Disagree & 61 & 18.6 \\
& Total & 324 & 100.0 \\
\hline
\end{tabular}

Table 4, reflect the expatriates' perceptions in regards to the availability of information, in other words the quality of the disclosure level of the insurance company, which also reflect a clear disclosure regarding the feature of their policy. The findings were surprised that $132(40.4 \%)$ and $61(18.6 \%)$ expatriates replied with disagree and strongly disagree respectively. Such findings come in contrast with IAIS (2002), as IAIS asserted that disclosure is a prudential aspect for proper efficiency of the financial market. It's also came in contrast with the hypothesis 4 , as the disclosure level of the insurance company is not good enough to reflect the required information needed by expatriates for their health insurance policy. However, the results agreed with the findings of Alnemer (2012) that insurance companies in Saudi Arabia are in need of effective disclosure mechanisms to reflect the features of different insurance products.

6.3 Price of the Health Insurance Policy

Table 5. Perception of the price of the health insurance policy you have

\begin{tabular}{llll}
\hline \multirow{4}{*}{ Valid } & Options & Frequency & Percent \\
\cline { 2 - 4 } & Very Cheap & 12 & 3.7 \\
& Cheap & 12 & 3.7 \\
& Natural & 136 & 41.9 \\
& Expensive & 108 & 33.5 \\
& Very Expensive & 56 & 17.1 \\
& Total & 324 & 100.0 \\
\hline
\end{tabular}

Table 5, discuss expatriates' opinion in regards to the price of the health insurance policy they possess. The findings reflected that $108(33.5 \%)$ and $56(17.1 \%)$ expatriates answer with expensive and very expensive for the price of the health insurance they possess. Such findings indicated, despite the fact that CEBHI made health insurance obligatory for expatriates, many employers refuse to offer a health insurance policy to their expatriates' employees because of the higher premium price. The answers is not surprised as Kasnawi (2008), asserted that expatriates in Saudi Arabia are working in jobs for which they are overqualified; most are not employed in a job that reflects their actual education (low skills required for the job compared to a high personal educational level). Expatriates replies also comes in parallel with hypothesis 5, that agreed on the higher price of health insurance policies offered.

6.4 Out- Of Pocket Claim Payments

Table 6. Insufficient income to handle medical bills in case of health insurance policy been declined

\begin{tabular}{llll}
\hline \multirow{4}{*}{ Valid } & Options & Frequency & Percent \\
\cline { 2 - 4 } & Agree & 113 & 34.8 \\
& Strongly Agree & 84 & 26.1 \\
& Natural & 74 & 22.7 \\
& Disagree & 19 & 5.9 \\
& Strongly Disagree & 34 & 10.6 \\
& Total & 324 & 100.0 \\
\hline
\end{tabular}


Table 6, Explores expatriates' financial capabilities to handle declined health insurance claims as health insurance payments through OOP lead to general financial stress. Accordingly, 84 (26.1\%) and 113 (34.8\%) expatriates receptively agreed and strongly agreed that their salary cannot handle medical bills in case of claims declined. Such indication comes in contrast with CEBHI regulations as they have identified the maximum co-payments an expatriates can pay with an amount not to exceed $20 \%$ of the invoice or SR 100 . If expatriates' employers adhered to this regulation, then the answers should be different as they are not required to pay more than SR 100 in each medical claim. Another assumption, it is that the health insurance policy partially covers some of expatriates raised claims. The reaming claims should be paid OOP. Their answers also came, in contrast with hypothesis 6 , as their salary can't handle OOP claims.

\subsection{Quality of Health Insurance Policy}

Table 7. I have a high quality health insurance policy, which shows no effect on the financial conditions of mine

\begin{tabular}{llll}
\hline & Options & Frequency & Percent \\
\cline { 2 - 4 } Valid & Strongly Agree & 9 & 2.8 \\
& Agree & 54 & 16.5 \\
& Natural & 103 & 31.7 \\
& Disagree & 110 & 34.2 \\
& Strongly Disagree & 48 & 14.9 \\
& Total & 324 & 100.0 \\
\hline
\end{tabular}

Table 7, Explores expatriates' opinion in regards the quality of the health insurance policy they possess. Accordingly, $110(34.2 \%)$ and 48 (14.9\%) expatriates respectively replies with disagree and strongly disagree. Such results strongly linked to the research efforts that asserted the health insurance coverage alone may not be significant enough to increase access for minorities due to variations in the quality of healthcare providers. Findings comes in contrast with hypothesis 7, as expatriates' health insurance reported a weak quality. If health insurance quality is weak, then it's expected to affect their financial conditions.

6.6 Expected benefits of Health Insurance to Expatriates

Table 8. Your Health insurance policy had a great benefit to you

\begin{tabular}{llll}
\hline \multirow{5}{*}{ Valid } & Options & Frequency & Percent \\
\cline { 2 - 4 } & Strongly Agree & 11 & 3.4 \\
& Agree & 30 & 9.3 \\
& Natural & 54 & 16.5 \\
& Disagree & 136 & 42.2 \\
& Strongly Disagree & 93 & 28.6 \\
& Total & 324 & 100.0 \\
\hline
\end{tabular}

Similar, to the discussion of the previous question, Table 8, Explores expatriates' perceptions if they witness any benefits out of the health insurance policy they possess. The findings indicated that, 136 (42.2\%) and 93 (28.6\%) expatriates answer respectively with disagree and strongly disagree. The findings come in contrast with CEBHI regulations, that it is mandatory for insurance companies not to determine the premium based on the income. It's also necessary for expatriates' employers to conduct a good quality contract with the insurance companies, as employers are less likely to provide a good health insurance coverage if the insurance coverage is very expensive. The results also come in contrast with hypothesis 8 , since the majority of expatriates clarifies that they gain less benefits from health insurance policy they possess.

\section{Discussion}

The main purpose of this paper is to explore the adherence of health insurance providers to the imposed regulations by CEBHI. Regulations that asserts the provision of a decent health insurance services to expatriates. Consequently, a certain question been distributed to expatriates at private sector exploring their perceptions about the quality of the health insurance they possess. The survey questionnaire and the hypotheses of the research structured based on a number of scientific researches effort as shown on the literature review. The researches effort were there to tackle a certain challenge that affects the quality of the health insurance industry 
and the end users such as expatriates. Challenges such as poor staff training or poor standards of selling especially selling through agencies, rare service quality measurement, maintain a balance between cost, inaccessibility to healthcare due to financial barriers, quality and access to healthcare. The research findings were astonishing. The majority of expatriates $171(52.8 \%)$ bought their health insurance policy from insurance intermediaries. Surprisingly, $222(68.6 \%)$ expatriates wish to buy their health insurance policy from the insurance company itself rather than intermediaries. Such findings show a hesitation among expatriates to deal with intermediaries. Which indicates intermediaries' weak knowledge about health insurance business. Its mandatory for health insurance providers to comply with SAMA regulations, that intermediaries shall act in an honest, transparent and fair manner to fulfill their obligations towards policyholders and the insurance company (SAMA, 2008). The previous findings were supported by another valid evidence, that 232 (71.7\%) expatriates show their needs of an education lessons about the health insurance policy they possess. Hence, its mandatory for health insurance providers to comply with SAMA regulations that Intermediaries shall also be knowledgeable of the insurance business up-to-date and be informed of the products and services offered by the company (SAMA, 2008). Expatriates also clarifies that there is no rigid and valid disclosure system available to reflect the feature of health insurance policy. As, 132 (40.4\%) and 61 (18.6\%) expatriates reply respectively with disagree and strongly disagree, for weak information availability. Its mandatory for health insurance provider to comply with IAIS regulations. IAIS asserted that disclosure is a prudential aspect for proper efficiency of the financial market IAIS (2002). Furthermore, despite the fact that CEBHI had made it obligatory for employers to provide health insurance services for expatriates to remove expatriates' financial hardship bearing the cost of medical expenses. Thus, $108(33.5 \%)$ and $56(17.1 \%)$ expatriates respectively answers with expensive and very expensive for the price of the health insurance they possess. This proves the research findings made by Kasnawi (2008) that employers avoid providing health insurance to expatriates because of higher premium price. It's vital for health insurance to adhere to CEBHI regulations to provide health insurance to expatriates. As the majority of sampled expatriates $59 \%$ having a salary of SR 2000 (\$533.33) or less, which considered is low. Another unfortunate finding was the majority of expatriates, $84(26.1 \%)$ and $113(34.8 \%)$ answers with agreed and strongly agreed respectively, as their monthly salary couldn't handle the OOP medical expenses if health insurance claims been declined. This clarifies that expatriates are paying more than what been reflected on CEBHI regulations of maximum co-payments not to exceeds $20 \%$ of the invoice or SR100, or assigned copayments might exceed $20 \%$ of the total claims. In regards the quality of health insurance policy, the majority of expatriates $110(34.2 \%)$ and $48(14.9 \%)$ replies with disagree and strongly disagree respectively. Weak quality indicates that employers might refuse or reduce the quality of health insurance due to rising premiums. Such an act might be as results lower job characteristics. Lower health insurance quality will reduce the expected benefits. Consequently, $136(42.2 \%)$ and $93(28.6 \%)$ expatriates, answers with agree and strongly agree respectively for an obvious shortage in the benefits gaining from health insurance policy. This result shows a clear deviation from CEBHI regulations. Health insurance providers, seems to determine insurance policy based on employees' income, and not on risk pooling or the need.

\section{Conclusion}

This paper explored the adherence of insurance companies to the regulations posted by CEBHI to provide a decent health insurance services to expatriates, who works at private sectors in Saudi Arabia. The results were astonishing, the majority of expatriates bought their health insurance from intermediaries. However, expatriates show unwillingness to deal with intermediaries, they prefer to buy insurance policy directly from the insurance company itself. This indicates that intermediaries have a weak knowledge about health insurance business. Expatriates also express their needs for an education program to learn more about health insurance policy they possess. As they clarify there is no rigid and valid disclosure system available to reflect the feature of health insurance policy. The price of health insurance policy was described by expatriates as expensive as the majority received a salary of SR 2000 or less. Of which expatriates couldn't handle OOP medical expenses if health insurance claims declined. This indicates that expatriates are paying more than $20 \%$ of the assigned maximum co-payment by CEBHI. The quality of health insurance policy was described as weak, which might affect expatriates' future financial conditions, since it has a shortage in benefits. From the above findings, a number of challenges seem to be exists. In common these challenges can be concluded as a high demand on health care services resulting from free services, poor accessibility to good quality health insurance due to expensive premium, lack of a national health information system, and the underutilization of the potential of electronic health strategies. Hence, it is highly recommended to develop an accurate and sophisticated diagnostic model for measuring service quality in the health insurance industry. The model shall measure and control overall compliance of CEBHI and other health care regulators in favor of protecting expatriates' rights to get the health insurance products. The model will have a target of uniting scattered health care regulations imposed by different 
regulators into one system for easy adherence and compliance by health care and insurance providers. To assure valuable health insurance policy for expatriates assuring a valid health insurance disclosure system reflecting features and benefits. The system shall also assure similar health care treatment regardless of income and risk encountered, as employers should bear health insurance premiums.

\section{References}

Al-Ahmadi, H., \& Roland, M. (2005). Quality of Primary Healthcare in Saudi Arabia: A comprehensive Review. International Journal for Quality in Health Care, 17, 331-346. https://doi.org/10.1093/intqhe/mzi046

AlNemer, H. (2015a). Intermediaries Are Poor Market Conduct And Disclosure Chanel: An Empirical Study On Saudi Arabia. European Journal of Business and Social Sciences, 4(2).

AlNemer, H. (2015b). Participants' Knowledge and Educational Background about Takaful Products \& Services: An Empirical Study on Saudi Arabia. International Journal of Business, Economics and Law, 7(1).

AlNemer, H. (2015c). Participants' Perceptions about Takaful Operators Disclosure System: An Empirical Study on Saudi Arabia. Islamic Finance, Performance and Efficiency. V3. Gerlach Press. Germany.

Al-Omar, D. H. M. (2005). Infrastructure for Saudi Health Insurance. $I^{\text {st }}$ International Conference in Health Economics and Endowment. Riyadh, King Faisal Specialist Hospital and Research Centre.

Al-Osaimi, M. N. (2009). The Equity in Access to Health Care Services, 2008-2009. Arab Board in Community Medicine. Damascus.

Al-Rabeeah, O. (2000). Cooperative Health Insurance. Is it the best alternative? Cooperative Health Insurance. Dammam, Magrabi.

Anderson, Eugene W., \& Mary W. Sullivan. (1993). The Antecedents and Consequences of Customer Satisfaction. Marketing Science, 12, 125-143. https://doi.org/10.1287/mksc.12.2.125

Ansari, Z. A. (2012). An empirical analysis of risk perception, remedial measures and behaviour of people in Saudi Arabia towards insurance. African Journal of Business Management, 6(10), 3733-3744.

Ansari. (2011). Analysis of the impact of reforms on the insurance industry of Saudi Arabia. Interdisciplinary Journal of Research in Business, 1(8), 28-37.

Bakhuti, S., Christopher, J. L., \& Adams, O. B. (2003). Beyond Access and Utilization: Defining and Measuring Health System Coverage. Geneva, WHO.

Bundorf, M. K. (2000). Employee Demand for Health Insurance and Employer Health Benefit Choices. (PhD) Managerial Science and Applied Economics. University of Pennsylvania.

Cabinet of Ministers. (1999b). Cooperative Health Insurance Law Updated. Riyadh, Saudi e-Government.

Carlson, M. J., Devoe, J., \& Wright, B. J. (2006). Short-term impacts of coverage loss in a Medicaid population: Early results from a prospective cohort study of the Oregon Health Plan. Annals of Family Medicine, 4, 391-398. https://doi.org/10.1370/afm.573

CCHI. (2009a). Annual Report. Riyadh, Council of Cooperative Health Insurance. Retrieved from http://www.cchi.gov.sa/Studies/Reports/AnnualReports/Pages/default.aspx

CCHI. (2009b). Regulations for Cooperative Health Insurance System. The Council of Cooperative Health Insurance.

CED. (2006). The Employer-Based Health-Insurance System (EBI) Is At Risk? What We Must Do About It? CED Research and Policy Committee. Washington, DC, CED.

Collard, S. (2001). Consumers in the Financial Market: Financial Services Consumer Panel Annual Survey of Consumers 2000. Financial Services Consumer Panel. London.

Cooper, R. W., \& Frank, G. L. (2001). Key Ethical Issues Facing the Property and Casualty Insurance: Has a Decade Made a Difference. CPCU Journal, 54(2), 99-111.

Crane, F. G. (1980). Insurance Principles and Practices. New York John Wiley Sons, Inc. 1980.

Criel, B., \& Waelkens, M. P. (2003). Declining subscriptions to the Maliando Mutual Health Organisation in Guinea-Conakry (West Africa): what is going wrong? Social Science \& Medicine, 57, 1205-1219. https://doi.org/10.1016/S0277-9536(02)00495-1

Cutler, D. M. (2003). Employee Costs and the Decline in Health Insurance Coverage. NBER/Frontiers in Health Policy Research. MIT Press. 
Cutler, D. M., \& MAdrian, B. C. (1998). Labor Market Responses to Rising Health Insurance Costs: Evidence on Hours Worked. The RAND Journal of Economics, 29, 509-530. https://doi.org/10.2307/2556102

Darcy, K. T. (1996). Can Ethics be Taught in the Insurance Industry. National Underwriter, 100, 35.

Diacon, S. R., \& Watkins, T. (1995). Insurance Marketing.

Elliott, C. M., \& Vaughan, E. J. (1972). Fundamentals of Risk and Insurance. New York: John Wiley \& Sons Inc.

Fiscella, K., Franks, P., Doescher, M. P., \& Saver, B. G. (2002). Disparities in health care by race, ethnicity, and language among the insured: Findings from a national sample. Medical Care, 40, 52-59. https://doi.org/10.1097/00005650-200201000-00007

Francis, M. (2002). Standards in Our Industry-Past, Present and Future. The Insurance Institute (London).

Friedman, S. (2001a). RIMS plans to have third quality scorecard. National Underwriter, 105, 3-22.

Friedman, S. (2001b). RIMS launches quality process. National Underwriter, 105(19), 3-29.

Friedman, S. (2002). You can never take CSRs for granted. National Underwriter, 106, 49-50.

Fronstin, P., R. (2000). Small Employers and Health Benefits: Findings from the 2000 Small Employer Health Benefits Survey. Employee Benefit Research Institute Issue Brief Number 226. Washington, D.C.

Gow, R. (2000). Cashing on B2B. Canadian Underwriter, 67(4), 42-44.

Hansen, S. M. (2001). The Increasing Number of Working Uninsured in the City of Philadelphia: An Analysis of Small Business and Employee Choices (PhD). Temple University.

IAIS (2002). Guidance Paper on Public Disclosure by Insurers.

IAIS. (2011). Insurance Core Principles, Standards, Guidance and Assessment Methodology.

ILO. (2008). Social Health Protection: An ILO Strategy towards universal access to health care. Social Security Policy Briefings. Geneva, International Labour Office.

Institute of Medicine. (1993). Access to Health Care in America, Washington, D.C. National Academy of Sciences.

Kapur, K. (2004). The Impact of the Health Insurance Market on Small Firm Employment. Journal of Risk \& Insurance. Blackwell Publishing Limited.

Kasper, J. D., Giovannini, T. A., \& Hoffman, C. (2000). Gaining and Losing Health Insurance: Strengthening the Evidence for Effects on Access to Care and Health Outcomes. Medical Care Research and Review, 57, 298-318. https://doi.org/10.1177/107755870005700302

Lillie-Blanton, M., \& Hoffman, C. (2005). The role of health insurance coverage in reducing racial/ethnic disparities in health care. Health Affairs, 24, 398-408. https://doi.org/10.1377/hlthaff.24.2.398

McCabe, D., Knights, D., \& Wilkinson, A. (1997). Financial Services - Every Which Way but Quality? Journal of General Management, 22(3), 53-73. https://doi.org/10.1177/030630709702200305

Meltzer, S. R. (1997). Insurance industry's quality must be a two-way street. Risk Management, 44, 60.

Mills, A. (2007). Strategies to Achieve Universal Coverage: Are There Lessons from Middle Income Countries?

Morrisey, M. A., Jensen, G. A., \& Morlock, R. J. (1994). Small employers and the health insurance market. Health Aff., 13, 149-161.

Newacheck, P. W., Stoddard, J. J., Hughes, D. C., \& Pearl, M. (1998). Health Insurance and Access to Primary Care for Children. New England Journal of Medicine, 338, 513-519. https://doi.org/10.1056/NEJM199802193380806

Oakland, J. S. (1995). Total quality management, text with cases. Oxford: British Library.

Penchansky, R., \& Thomas, J. W. (1981). The Concept of Access: Definition and Relationship to Consumer Satisfaction. Medical Care, 19, 127-140. https://doi.org/10.1097/00005650-198102000-00001

Pratt, J. (2002). Recruiting starts with the culture. National Underwriter, 106, 5-6.

Saaty S. A., \& Ansari, Z. A. (2011). Factors critical in marketing strategies of insurance companies in Saudi Arabia. International Journal of Marketing Studies, 3(3), 104-121. https://doi.org/10.5539/ijms.v3n3p104

SAMA. (2008). Insurance Market Code of conduct Regulations.

SAMA. (2011). Insurance Intermediaries Regulation. 
Schieber, G. J. (2005). Health Financing Issues in the Kingdom of Saudi Arabia. $I^{\text {st }}$ International Conference in Health Economics \& Endowment. Riyadh, King Faisal Specialist Hospital and Research Centre.

Sekhri, N., \& Savedoff, W. (2005). Private Health Insurance: Implications for Developing Countries. Bulletin of the World Health Organization, 83(8).

Sherden, W. (1987). The erosion of service quality. Best's Review, 88(5), 22.

Siddiqui, M. H., \& Tripti, G. S. (2010). Analyzing Customer Satisfaction with Service Quality in Life Insurance. Journal of Targeting, Measurement and Analysis for Marketing, 18(3/4), 221-238. https://doi.org/10.1057/jt.2010.17

Simmy, M. M. (2005). Exploration of SERVQUAL's efficacy via the Diagnosis and Improvement of Service Quality in Kenya's Insurance Industry. Unpublished Ph.D. Thesis. Lancaster University.

Simon, K. I. (2008). Where Do the Sick Go? Health Insurance and Employment in Small and Large Firms. Southern Economic Journal. Southern Economic Association.

Smith, R. L. (1996). Insurance Industry Must be Pro-active on Ethics. National Underwriter, 1(100), 43.

Stafford, M. R., Stafford, T. F., \& Wells, B. P. (1998). Determinants of Service Quality and Satisfaction in the Auto Casuality Claims Process. The Journal of Service Marketing, 12(6), 426-440. https://doi.org/10.1108/08876049810242687

Survey Research Associates. (1992). A Presentation of the Main Findings of Persistency Research. Survey Research Associates. London.

Tanahashi, T. (1978). Health service coverage and its evaluation. Bulletin World Health Organ., 56(8).

Voelker, P. M. (2000). Closing the gap: Insurance and Technology. Insurance industry Information technology. 25, 33-38.

Waidmann, T. A., \& Rajan, S. (2000). Race and ethnic disparities in health care access and utilization: An examination of state variation. Medical Care Research and Review, 57, 55-84. https://doi.org/10.1177/1077558700057001S04

Zuvekas, S. H., \& Tallaferro, G. S. (2003) Pathways to access: Health insurance, the health care delivery system, and racial/ethnic disparities, 1996-1999. Health Affairs, 22, 139-153. https://doi.org/10.1377/hlthaff.22.2.139

\section{Copyrights}

Copyright for this article is retained by the author(s), with first publication rights granted to the journal.

This is an open-access article distributed under the terms and conditions of the Creative Commons Attribution license (http://creativecommons.org/licenses/by/4.0/). 